Pesq. Vet. Bras. 37(11):1205-1212, novembro 2017 DOI: $10.1590 / \mathrm{S} 0100-736 \mathrm{X} 2017001100004$

\title{
Tipologia de manejo de ordenha: análise de fatores de risco para a mastite subclínica ${ }^{1}$
}

\author{
Maichel J. Lange ${ }^{2 *}$, Maximiliane A. Zambom², Magali S.S. Pozza ${ }^{3}$, Gilberto \\ H. Simões ${ }^{2}$, Tatiane Fernandes ${ }^{4}$, Rodrigo C.R. Tinini ${ }^{2}$, Josias Fornari ${ }^{5}$ \\ e Fernando A. Anschau ${ }^{5}$
}

\begin{abstract}
Lange M.J., Zambom M.A., Pozza M.S.S., Simões G.H., Fernandes T., Tinini R.C.R., Fornari J. \& Anschau F.A. 2017. [Typology of milking management: analysis of risk factors for subclinical mastitis.] Tipologia de manejo de ordenha: análise de fatores de risco para a mastite subclínica. Pesquisa Veterinária Brasileira 37(11):1205-1212. Programa de Pós-Graduação em Zootecnia, Universidade Estadual do Oeste do Paraná, Rua Pernambuco 1777, Centro, Marechal Cândido Rondon, PR 85960-000, Brazil. E-mail: maichel_jl@hotmail.com

Despite the produced milk volume, its quality is one of the barriers for technological development and consolidation of the dairy industry in Brazil. Among the barriers is the milk somatic cell count, which is the indicator used in most control programs and prevention of mastitis. In order to identify characteristics in the management of milking and to quantify risk factors that increase subclinical mastitis and its main bacterial agents, data were collected in situ on dairy farms in western Paraná. The data collection consisted in the application of two questionnaires, in accompanying a milking procedure, and in collection of CMT positive milk samples from three cows. Using the statistical method of multiple correspondence analysis (MCA) we came to a total of 12 variables to be studied, and to the formation of dimension 1 and 2 with respectively $28.54 \%$ and $21.06 \%$ of the explained variance. With the hierarchical ascending classification analysis it was possible to reduce the initial population of 112 cows to produce four homogeneous groups (G1, G2, G3, G4). The milking handling characteristics, as type of milking, drying teats before milking, treatment for cases of clinical mastitis, milker's hand hygiene and as training of officers, were identified as risk factors for subclinical mastitis with isolation of a coagulase negative Staphylococcus, which was the most prevalent agent in milk samples of subclinical mastitis.
\end{abstract}

INDEX TERM: Milking management, CCS, CMT, subclinical mastitis, milk, dairy cows.

RESUMO.- Apesar do volume de leite produzido, a qualidade da matéria-prima é um dos maiores entraves ao desenvolvimento tecnológico e à consolidação da indústria de laticínios no Brasil. Dentre os entraves, toma destaque a contagem de células somáticas do leite, que é o indica-

\footnotetext{
${ }^{1}$ Recebido em 15 de abril de 2016.

Aceito para publicação em 11 de janeiro de 2017.

${ }^{2}$ Programa de Pós-Graduação em Zootecnia, Universidade Estadual do Oeste do Paraná (Unioeste), Rua Pernambuco 1777, Centro, Marechal Cândido Rondon, PR 85960-000, Brasil. *Autor para correspondência: maichel_jl@hotmail.com

${ }^{3}$ Programa de Pós-Graduação em Zootecnia, Universidade Estadual de Maringá (UEM), Av. Colombo 5.790, Jd. Universitário, Maringá, PR 87020900, Brasil.

${ }^{4}$ Programa de Pós-Graduação em Zootecnia, Universidade Federal de Lavras (UFLA), Lavras, MG 37200-000, Brasil.

${ }^{5}$ Curso de Zootecnia, Unioeste, Rua Pernambuco 1777, Centro, Marechal Cândido Rondon, PR 85960-000, Brasil.
}

dor mais usado em programas de controle e prevenção da mastite em todo o mundo. Com objetivo de identificar características no manejo de ordenha e quantificar fatores de risco que elevam a mastite subclínica e seus principais agentes causadores, realizou-se coleta de dados in loco em propriedades leiteiras na região Oeste do Paraná, coletas que consistiam na aplicação de dois questionários guia semi-estruturados, acompanhamento de uma ordenha e coleta de leite de três vacas que apresentassem o teste de CMT positivo. Com a utilização do método estatístico de análise de correspondência múltipla (ACM) chegou-se a um montante de 12 variáveis a serem estudadas e a formação das dimensões 1 e 2 com 28,54\% e 21,06\% da variância explicada respectivamente. Com a análise de classificação hierárquica ascendente permitiu reduzir o universo inicial de 112 vacas para quatro grupos homogêneos de produção (G1, G2, G3, G4). As características de manejo de ordenha: 
tipo de ordenha, secagem dos tetos antes da ordenha, tratamento para casos de mastite clínica, higiene das mãos do ordenhador e treinamento dos ordenadores foram identificados como fatores de risco para mastite subclínica com isolamento do agente Staphylococcus coagulase negativo, o qual foi o agente mais prevalente nos isolamentos microbiológicos das amostras de leite com mastite subclínica.

TERMOS DE INDEXAÇÃO: Manejo de ordenha, CCS, CMT, mastite subclínica, bovinos.

\section{INTRODUÇÃO}

A produção de leite no Brasil constitui uma das principais atividades agropecuárias em função de sua importância social e econômica, sendo um dos maiores setores de geração de renda nacional e arrecadação tributária (IBGE 2016). Apesar do grande volume de leite produzido, a qualidade do leite cru ainda é um dos maiores entraves ao desenvolvimento tecnológico e à consolidação da indústria de laticínios no Brasil, a qual é diretamente prejudicada pela alta contaminação microbiológica e que interfere diretamente na qualidade do leite pasteurizado ou destinado à produção de derivados (Dumalisile et al. 2005, Nero et al. 2005, Mattos et al. 2010).

De maneira geral, a baixa qualidade do leite pode ser atribuída a deficiências no manejo, à higiene no processo de ordenha, à sanidade da glândula mamária e à manutenção e desinfecção inadequada dos equipamentos (Nero et al. 2005). Por isso, cuidados higiênicos para evitar a contaminação do leite devem ter início na ordenha e seguir até o seu beneficiamento (Santana et al. 2001).

Devido às deficiências supracitadas tem-se a elevação e prevalência da mastite sub clínica, que pode estar relacionada ao manejo antes, durante e após a ordenha. Diante disso, ressalta-se a importância do correto manejo de ordenha e procedimentos adequados de higienização e desinfecção do ambiente, do animal, do profissional e de todos os utensílios utilizados (Brasil 2011).

Em programas de controle e prevenção de mastite, deve-se levar em consideração não apenas os fatores de risco ligados diretamente ao animal, ambiente, manejo e ao equipamento de ordenha, é necessário suporte tecnológico acessível que auxilie no controle e na erradicação de determinados patógenos (Coentrão et al. 2008).

Entre os agentes de origem infecciosa causadores das mastites o microrganismo Staphylococcus spp (Taponen \& Pyörälä 2009, Mota et al. 2012) é a bactéria mais detectada. Entre elas, as espécies coagulase negativas comumente isoladas no leite bovino, são consideradas como patógenos secundários, podendo causar reações inflamatórias moderadas na glândula mamária, levando aos altos índices de mastites subclínicas no rebanho.

O objetivo proposto no presente trabalho foi de caracterizar o manejo e práticas realizadas durante a ordenha, com isso quantificar os fatores de risco que elevam os níveis da mastite subclínica no rebanho e os principais agentes causadores da mesma, tendo como ênfase o Staphylococcus coagulase negativo. Com a identificação dos possíveis fatores de riscos para o aparecimento de mastites sub clinicas, poderemos elaborar programas de prevenção de controle adequados para a enfermidade em questão, melhorando assim a produtividade e consequentemente a lucratividade do sistema de produção.

\section{MATERIAL E MÉTODOS}

A partir de um universo de 735 produtores de leite foi realizada a amostragem de 73 rebanhos bovinos leiteiros, localizados na região Oeste do estado do Paraná e representando aproximadamente $10 \%$ dos sistemas de produção (Lange et al. 2016). A coleta de dados foi realizada durante visita in loco, entre os meses de setembro a dezembro de 2012, primeiramente utilizando questionário-guia semiestruturado. Também durante a mesma vista acompanhou-se uma ordenha na qual foi realizada o teste de CMT (California Mastitis Test) em parte do rebanho leiteiro até se conseguir coletar amostras de leite de três vacas que apresentassem resultado positivo para o teste. Para essas vacas CMT positivo, também se coletou informações do animal como tempo de lactação, número de lactações, produção e histórico de mastite.

O questionário-guia semiestruturado continha questões sobre informações gerais da propriedade, do manejo durante a ordenha enfatizando os procedimentos utilizados antes, durante e após a mesma, assim como higiene empregada e o manejo das vacas.

Posteriormente, as respostas do questionário foram tabuladas de forma a gerar uma matriz na qual as linhas corresponderam aos sistemas de produção leiteira e as colunas corresponderam às variáveis. As categorias referentes a cada variável, para que pudesse ser realizada a análise de correspondência múltipla, foram transformadas e codificadas (Crivisqui 1995, Mingoti 2005). $\mathrm{Na}$ seleção das variáveis, foram mantidas as que obtiveram os maiores escores de contribuição descrita em termos de variância explicada (Kubrusly 2001) e ajuste fiel aos dados originais ( $\alpha$ de Crombach $>0,75)$. A seleção dessas variáveis obedeceu ao conceito de criação dos "construtos", ou seja, um esforço no sentido de dar significado estatístico a um conceito que se deseja avaliar (Le Roux \& Rouanet 2010).

A determinação das variáveis explicativas dos sistemas de produção foi feita por meio da técnica de estatística multivariada, para dados qualitativos denominada: Análise de Correspondência Múltipla - ACM (Smith et al. 2002, Lebart et al. 2004). Utilizou-se o software Statistical Package for the Social Sciences (SPSS-v.18) para análise.

Como ferramenta complementar, foi realizada a análise de clusters (CHA), que consistiu em agrupar as vacas em lactação que apresentavam mastite subclínica durante o teste de CMT. A representação gráfica dos clusters no plano fatorial só foi possível utilizando as dimensões formadas na ACM através de seus autovalores, simplificando assim o campo de visão dos grupos formados pelos animais estudados.

Já o leite coletado das vacas CMT positivo foi armazenado em frascos estéreis de $100 \mathrm{~mL}$ e transportados em caixas térmicas (aprox. $5^{\circ} \mathrm{C}$ ) até o Laboratório de Microbiologia da Universidade Estadual do Oeste do Paraná (Unioeste) onde foram analisados no mesmo dia.

Primeiramente prepararam-se diluições decimais seriadas até $10^{-3} \mathrm{em}$ frascos contendo água peptonada estéril e, em seguida alíquotas correspondentes a $0,1 \mathrm{~mL}$ de cada diluição foram transferidas para placas de petri contendo Ágar Sangue e incubadas a $37^{\circ} \mathrm{C}$ durante 48 horas. Após fez-se as contagem e anotações das colônias típicas e atípicas observando as características morfológicas das colônias como tamanho, tipo, coloração e presença de hemólise de somente uma das placas por animal que continham de 25 a 250 unidades formadores de colônias (UFC), sendo multiplicado pelo inverso da diluição e por 10 , resultando em $\mathrm{CBT} / \mathrm{mL}$ (Lancette et al. 1992). 
Foram transferidas cinco colônias típicas e atípicas para tubos de hemólise contendo $3 \mathrm{~mL}$ de caldo infuso cérebro coração (BHI) e incubadas a $37^{\circ} \mathrm{C}$ por 24 horas. A partir de cada cultivo foram submetidas à prova de coloração de gram e à prova de catalase. Todos os resultados positivos quanto à prova de catalase foram submetidos à prova de coagulase (MacFaddin 1980).

E para interpretação das análises microbiológicas utilizou-se a análise de regressão logística múltipla, tendo como variável dependente (resposta) a classificação dos rebanhos de acordo com os fatores de risco de mastite subclínica relacionados a contaminação por Staphylococcus coagulase negativa. Foram realizadas análises bivariadas para testar associações entre cada variável independente do modelo de regressão logística. Os critérios de decisão para a escolha das variáveis testadas no modelo de regressão logística foram aqueles que ofereciam explicação coerente para o aumento da mastite subclínica relacionados a contaminação por Staphyococcus coagulase negativa e que na associação apresentaram $\mathrm{P}<0,05$. Após a seleção do modelo final de regressão logística, foi observado o coeficiente beta $(\beta)$ de cada variável independente para se estimar o grau de risco (Odds ratio; OR). Determinando assim a probabilidade de ocorrência de mastite subclínica causada por Staphylococcus coagulase negativa com os fatores de riscos estudados, através da estimativa do risco relativo (Odds ratio, OR) (Frankena \& Graat 1997, Hosmer \& Lemeshow 2000).

\section{RESULTADOS}

Com as variáveis coletadas através do questionário-guia semiestruturado e utilização do método estatístico de análise de correspondência múltipla (ACM) chegou-se a um montante de 12 variáveis a serem estudadas. Os resultados referentes à estatística encontradas para dimensões 1 e 2 são um meio de se resumir essas variáveis. Para Dimensão1 (D1) atingiu-se $28,54 \%$ da variância explicada e para Dimensão 2 (D2) 21,06\% da variância explicada que acumuladas totalizam 49,6\% da variância (Quadro 1).

A relação entre as variáveis para a formação das duas

Quadro 1. Contribuições dos componentes da Análise Fatorial aos autovalores e porcentagem de variância explicada

\begin{tabular}{cccc}
\hline Componentes & Autovalores & \% da Variância & Variância Acumulada \\
\hline 1 & 7,09 & 28,54 & 28,54 \\
2 & 5,73 & 21,06 & 49,6
\end{tabular}

dimensões e contribuição em termos de autovalores, que explicam a caracterização do manejo no momento da ordenha que elevam o risco de aparecimento de mastite subclínica está na Figura 1.

As variáveis que mais contribuíram para a formação da dimensão 1 foram: pré e pós-dipping, local que as vacas vão após a ordenha e frequência de limpeza da sala de orde-

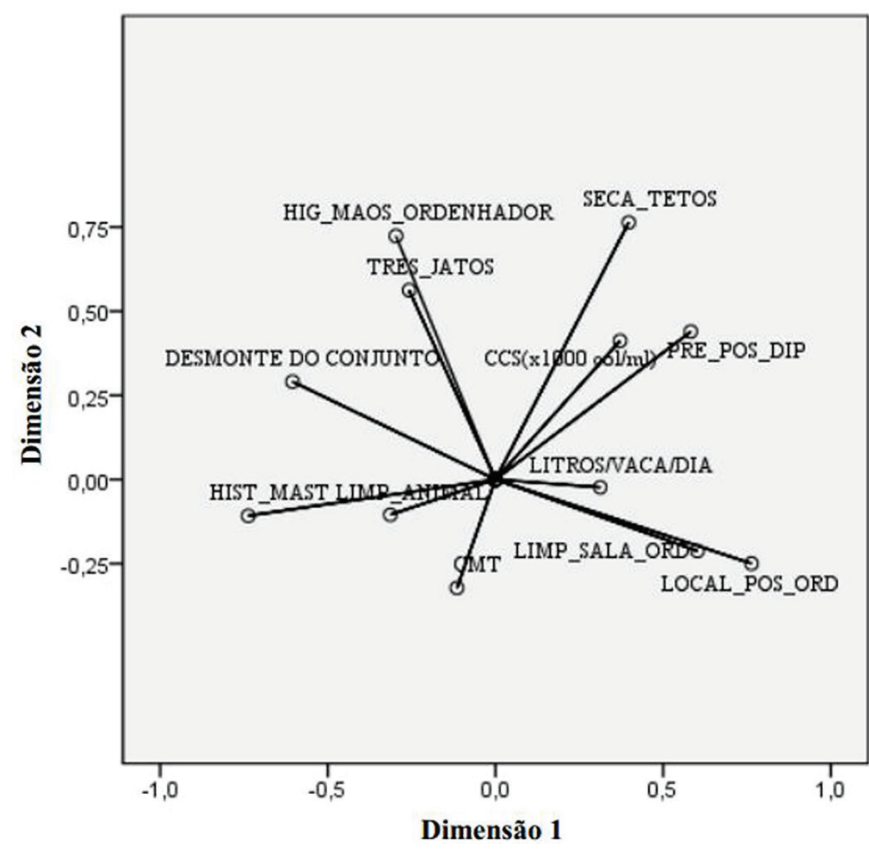

Fig.1. Representação das variáveis e suas contribuições para formação das duas primeiras dimensões da ACM. CCS = Contagem de células somáticas, PRODUÇÃO/VACA/DIA = produção em Litros/vaca/dia, CMT = California Mastitis Test, HIST_MAST = histórico de mastite, LIMP_ANIMAL = higiene dos animais antes da ordenha, TRES_JATOS = examina 3 jatos, PRÉ_PÓS_DIP = realiza pré e pós-dipping, SECA_TETOS = faz a secagem dos tetos, LOCAL_PÓS_ORD = local em que as vacas permanecem após a ordenha, DESMONTE_CONJ_LIMP = ocorre desmonte do conjunto após a ordenha, LIMP_SALA_ORD = higiene da sala de ordenha, HIG_MÃOS_ORDENHADOR = higiene das mãos do ordenhador.

Quadro 2. Correlação entre as variáveis transformadas para a ACM

\begin{tabular}{|c|c|c|c|c|c|c|c|c|c|c|c|c|}
\hline & A & B & $\mathrm{C}$ & D & E & $\mathrm{F}$ & G & $\mathrm{H}$ & I & $\mathrm{L}$ & M & \\
\hline A & 1,000 & & & & & & & & & & & \\
\hline B & $-0,032$ & 1,000 & & & & & & & & & & \\
\hline $\mathrm{C}$ & 0,437 & 0,164 & 1,000 & & & & & & & & & \\
\hline D & $-0,290$ & $-0,078$ & 0,221 & 1,000 & & & & & & & & \\
\hline E & 0,046 & 0,142 & $-0,010$ & 0,201 & 1,000 & & & & & & & \\
\hline F & 0,011 & $-0,041$ & $-0,103$ & 0,149 & $-0,015$ & 1,000 & & & & & & \\
\hline G & 0,243 & 0,287 & 0,098 & $-0,284$ & $-0,115$ & 0,106 & 1,000 & & & & & \\
\hline $\mathrm{H}$ & 0,216 & 0,146 & $-0,092$ & $-0,361$ & $-0,297$ & 0,263 & 0,563 & 1,000 & & & & \\
\hline I & 0,199 & 0,226 & $-0,047$ & $-0,498$ & $-0,109$ & $-0,183$ & 0,275 & 0,063 & 1,000 & & & \\
\hline $\mathrm{J}$ & $-0,021$ & $-0,090$ & $-0,094$ & 0,309 & 0,219 & 0,272 & $-0,262$ & $-0,108$ & $-0,390$ & 1,000 & & \\
\hline $\mathrm{L}$ & 0,169 & 0,191 & $-0,059$ & $-0,295$ & $-0,125$ & $-0,281$ & 0,226 & $-0,011$ & 0,459 & $-0,218$ & 1,000 & \\
\hline M & 0,143 & $-0,063$ & $-0,084$ & 0,179 & 0,077 & 0,227 & 0,115 & 0,426 & $-0,398$ & 0,351 & $-0,164$ & 1,000 \\
\hline Autovalor & 2,854 & 2,106 & 1,504 & 1,238 & 0,872 & 0,768 & 0,644 & 0,574 & 0,488 & 0,392 & 0,350 & 0,210 \\
\hline
\end{tabular}

A = CCS(x1000 cel $/ \mathrm{mL}), \mathrm{B}=$ produção em Litros/vaca/dia, C = CMT, D = histórico de mastite, $\mathrm{E}=$ higiene dos animais antes da ordenha, $\mathrm{F}=$ examina 3 jatos, $\mathrm{G}=$ realiza pré e pós-dipping, $\mathrm{H}=$ faz a secagem dos tetos, $\mathrm{I}=$ local em que as vacas permanecem após a ordenha, $\mathrm{J}=$ ocorre desmonte do conjunto após a ordenha, $\mathrm{L}=$ higiene da sala de ordenha, $\mathrm{M}$ = higiene das mãos do ordenhador. 
nha. Já para a formação da dimensão 2, os maiores valores foram: examinam os três primeiros jatos, secam os tetos e higiene das mãos do ordenhador antes do processo de ordenha.

As saídas da ACM para as correlações entre as 12 variáveis analisadas para definir os riscos de mastite subclínica encontram-se no Quadro 2.

Na matriz de correlação destacam-se as seguintes variáveis: secagem dos tetos após a lavagem (SECA_TETOS) que teve boa correlação com pré e pós-dipping (PRE_POS_ DIP) e higiene das mãos do ordenhador antes da ordenha (HIG_MÃOS_ORDENHADOR), a qual apresentou correlação de 0,563 e 0,426 respectivamente. Higiene das mãos do ordenhador antes da ordenha (HIG_MÃOS_ORDENHADOR) também apresentou boa correlação com local em que as vacas vão pós ordenha (LOCAL_PÓS_ORD) e desmonte do conjunto de ordenha para limpeza (DESMONTE_CONJ_ LIMP) a qual apresentou correlação de 0,398 e 0,351, respectivamente. Entende-se local pós-ordenha, como sendo sala de alimentação ou piquete, onde que na sala de alimentação a vaca irá ficar um tempo se alimentado em pé possibilitando assim que o esfíncter do teto, que também serve de barreira para contaminação microbiológica, volte ao normal.

O histórico de mastite (HIST_MAST) também tem alta correlação com local em que as vacas vão pós- ordenha (LOCAL_PÓS_ORD) - 0,498 e desmonte do conjunto de ordenha para limpeza (DESMONTE_CONJ_LIMP) 0,309 de correlação.

Em se tratando dos valores médios de (CCS) em relação aos escores de (CMT) tem-se uma correlação de 0,437.

Na Figura 2, são demonstradas graficamente as relações entre as dimensões formadas (D1 e D2) e o agrupamento das vacas nas quais foram realizadas as coletas de dados. Através da análise de classificação hierárquica ascendente permitiu-se reduzir o universo inicial de 112 vacas para quatro grupos homogêneos de produção (G1, G2, G3, G4), os quais suas características estão descritas no Quadro 3. Os quadrantes obtidos a partir da intersecção dos eixos das dimensões 1 e 2 permitem interpretar os grupos de sistemas segundo as características ligadas a produção do leite de cada vaca.

No grupo 1 (G1), estão agrupados 20 animais com médias de CCS de $2578 \mathrm{mil} / \mathrm{cel} / \mathrm{mL}$ e de produção de $14 \mathrm{~L} /$ vaca/dia, sendo essas vacas alimentadas na sala de alimentação ou conduzidas à pastagem logo após a ordenha.

No grupo 2 (G2), os 48 animais apresentam média de

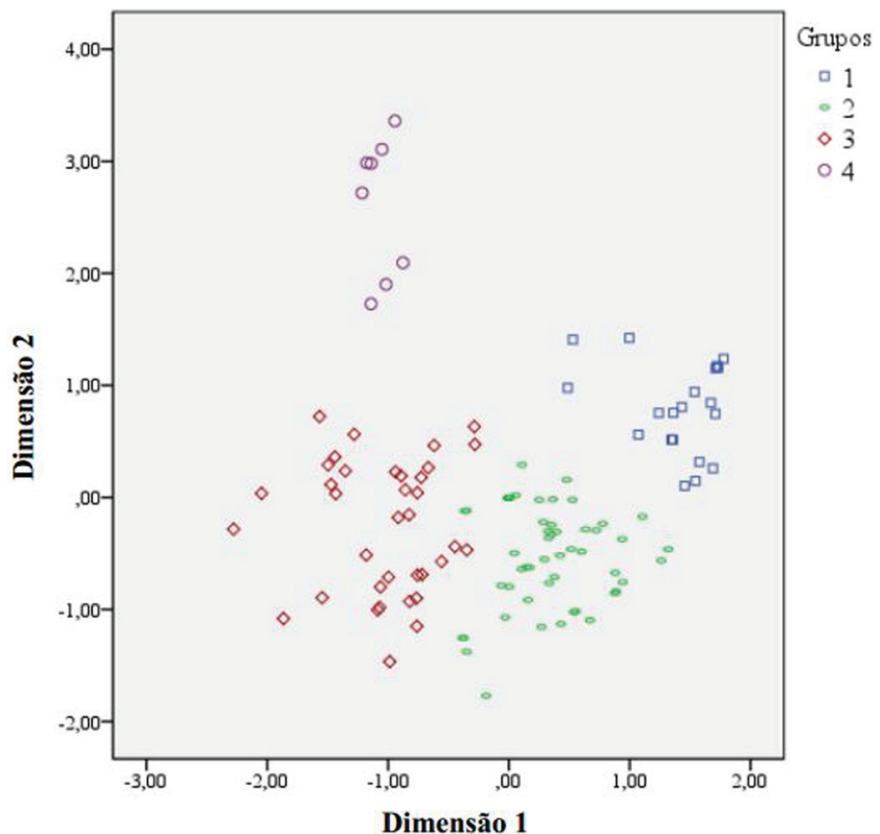

Fig.2. Representação fatorial da ACM e os agrupamentos dos animais de produção.

Quadro 3. Caracteristicas dos grupos formados através da análise de classificação hierárquica ascendente

\begin{tabular}{ccccc}
\hline Grupos & $\begin{array}{c}\mathrm{N}^{\circ} \text { animais } \\
\text { no Grupo }\end{array}$ & $\begin{array}{c}\text { Produção } \\
\text { Média/dia }\end{array}$ & $\begin{array}{c}\text { CCS Média } \\
\mathrm{mil} / \mathrm{cel} / \mathrm{mL}\end{array}$ & Caracteristica marcante \\
\hline G1 & 20 & $14 \mathrm{~L}$ & 2578 & $\begin{array}{c}\text { Ordenha>Sala de } \\
\text { G2 }\end{array}$ \\
G3 & 36 & 14L & 1509 & $\begin{array}{c}\text { Alimentação>Piquete Ordenha } \\
\text { Higienização sala de } \\
\text { ordenha esporádica }\end{array}$ \\
G4 & 8 & 12L & 1220 & $\begin{array}{c}\text { Histórico de mastite e não } \\
\text { realizavam pré e pós-dipping } \\
\text { Alimentação durante ordenha } \\
\text { erealizavam pré e pós-dipping }\end{array}$
\end{tabular}

Quadro 4. Número de amostras coletadas, médias de CCS, porcentagem de Staphylococcus spp. coagulase positiva, Staphyococcus coagulase negativa e Streptococcus spp. e outros, com base dos grupos de CMT

\begin{tabular}{lccccc}
\hline CMT & $\begin{array}{c}\text { No de } \\
\text { amostras }\end{array}$ & Média CCS & Staphylococcus & Staphylococcus & Streptococcus \\
\hline+ & 37 & 753.513 & $2,5 \%$ & $15,18 \%$ & $15,34 \%$ \\
++ & 55 & 1.683 .909 & $3,75 \%$ & $21,43 \%$ & $21,43 \%$ \\
+++ & 20 & 3.447 .000 & $1,79 \%$ & $7,32 \%$ & $8,75 \%$ \\
Total & 112 & & $8,04 \%$ & $43,93 \%$ & $48,03 \%$ \\
\hline
\end{tabular}

Coag.: Coagulase. 
Quadro 5. Modelo final de regressão logística com presença ou ausência de Staphylococcus coaulase negativo como variável dependente

\begin{tabular}{|c|c|c|c|}
\hline Fator de Risco & & OR & $\mathrm{P}$ \\
\hline Histórico de mastite & Sim X Não & 0,102 & $*$ \\
\hline Tipo de ordenha & Mecânica X Manual & 4,890 & $* *$ \\
\hline Higiene animal antes da ordenha & Sim X Não & 0,920 & NS \\
\hline Examinar os 3 primeiros jatos de leite & Sim X Não & 0,283 & $* *$ \\
\hline Pré e pós-dipping & Sim X Não & 0,346 & $*$ \\
\hline Secagem dos tetos antes da ordenha & Sim X Não & 2,026 & $*$ \\
\hline Local que as vacas vão após ordenha & Sala Alimentação x Piquete & 0,288 & $*$ \\
\hline Tratamento para casos de mastite clínica & Sim X Não & 1,801 & $*$ \\
\hline Desmonte do conjunto de ordenhadeira para limpeza & Sim X Não & 0,273 & $*$ \\
\hline Frequência de manutenção da ordenha & Meses & 0,920 & NS \\
\hline Higiene das mãos do ordenhador & Sim X Não & 1,051 & $* *$ \\
\hline Treinamento dos ordenhadores & Sim X Não & 1,418 & $*$ \\
\hline
\end{tabular}

produção igual ao G1 porém a média de CCS desse grupo ficou em $1509 \mathrm{mil} / \mathrm{cel} / \mathrm{mL}$. O G2 tem uma peculiaridade dentre todos os outros grupos, pois as salas de ordenha eram higienizadas esporadicamente.

0 grupo 3 (G3) é formado por 36 animais onde a média de produção desses fica em 11 L/vaca/dia e CCS de 1220 $\mathrm{mil} / \mathrm{cel} / \mathrm{mL}$. Nesse grupo todos as vacas apresentaram histórico de mastites anteriores e não se realizavam o pré e pós-dipping.

No grupo (G4), as vacas apresentaram médias de produção de 12 L/vaca/dia e CCS de 2936 mil/cel/mL. Nesse grupo todos os animais eram alimentados na sala de ordenha e se realizava pré e pós-dipping.

Posteriormente, realizou-se as análises microbiológicas das 112 amostras coletadas, das quais todas apresentaram crescimento bacteriano em ao menos uma das três diluições decimais.

Com as análises microbiológicas realizadas pode-se constatar que 8,04\% das amostras apresentaram crescimento de Staphylococcus spp. coagulase positiva (SCP), 43,9\% das amostras apresentaram crescimento de Staphylococcus spp. coagulase negativa (SCN) e que $48 \%$ apresentaram crescimento de Streptococcus spp. e outros (Quadro 4).

Os fatores de risco para mastite subclínica relacionados com o momento da ordenha para a presença do grupo de bactérias SCN são apresentados no Quadro 5, onde o valor de Odd's ratio representa o aumento da probabilidade de ocorrência de mastite subclínica. A variável com maior fator de risco identificado foi "Tipo de Ordenha". Observou-se que em rebanhos onde o tipo ordenha era pouco tecnificada (ordenha manual), as vacas apresentaram 4,890 vezes mais chance de estarem infectados com Staphylococcus coagulase negativos em relação ás vacas de propriedades onde o tipo de ordenha era mecânica. As variáveis "Secagem dos tetos antes da ordenha" (2,026 mais chances), "Tratamento para casos de mastite clínica" (1,801 mais chances), "Higiene das mãos do ordenhador" (1,051 mais chances) e "Treinamento dos ordenhadores" (1,418 mais chances) também apresentaram maior risco da probabilidade de ocorrência para mastite subclínica com a presença de SCN.

0 fator de risco relacionado à terapia com antibióticos identificado nesse estudo foi tratamento para mastites clínicas, pois a não execução desse procedimento, pode comprometer as estratégias de controle da mastite subclínica.

\section{DISCUSSÃO}

Os resultados referentes à estatística para as variáveis que assumem os maiores valores das dimensões 1 e 2, também são as que mais contribuem para a variância acumulada.

Na dimensão 1 as variáveis estão diretamente relacionadas a forma de prevenção de mastite (pré-dipping e pós-dipping) e o local onde ocorre a maior contaminação da mesma. Quanto a prevenção, o pré-dipping é um método eficaz no controle da mastite ambiental, embora apresente alguma eficácia no controle da mastite contagiosa. Já o pós-dipping é a prática isolada mais importante de controle de novas infecções intramamárias, que é a desinfecção dos tetos ao final da ordenha (Philpot \& Nickerson 2002).

Já na dimensão 2 essas variáveis de maior importância, inferem em práticas básicas na rotina de ordenha (examinar os primeiros jatos de leite, secagem dos tetos e higiene das mãos do ordenhador). Para Philpot \& Nickerson (2002) o correto manejo da rotina de ordenha é uma ótima medida de controle da mastite subclínica.

Segundo Fonseca \& Santos (2000), os princípios que orientam um correto manejo de ordenha incluem procedimentos de desinfecção dos tetos antes da ordenha, estimulação da ejeção e extração eficiente e rápida do leite e desinfecção dos tetos após a ordenha. Esses procedimentos, quando utilizados em conjunto, constituem a estratégia mais eficiente na prevenção da transmissão dos agentes contagiosos e, em menor escala, de agentes ambientais no momento da ordenha.

Utilizando os resultados da matriz de correlação, observa-se que os produtores que se preocupam em fazer uma correta rotina de ordenha, acabam fazend o todo o processo de higiene no pré e pós ordenha.

A conscientização do produtor quanto a higiene de suas mãos no momento da ordenha, lhe induz a também higienização do equipamento e da sala de ordenha, consequentemente, redução nos índices de mastites no rebanho e baixas reações positivas nos testes de CMT (Barkema et al. 1998, Reis et al. 2007). 
Brito et al. (1997) que estudaram a especificidade e sensibilidade do teste CMT em relação à CCS encontraram sensibilidade de $82 \%$ do CMT com a CCS acima de 500.000 células $/ \mathrm{ml}$, concluindo que o uso regular do CMT pode contribuir para melhorar o estado sanitário dos rebanhos, se os dados obtidos forem usados para orientar a adoção de medidas para o controle da mastite e se forem associadas práticas adequadas de manejo e higiene. Em estudo semelhante Silva et al. (2001) e Jorge (2005) encontraram relação significativa entre o de CMT e CCS respectivamente de $53 \%$ e $63 \%$ de correlação.

A correlação entre CMT e CCS encontrada no presente trabalho ficou abaixo quando comparada às correlações de outros trabalhos semelhantes, pois não se coletou leite de todas as vacas em lactação dos rebanhos estudados, mas somente de algumas vacas que apresentaram CMT positivo. Porém, em relação às medias de CCS, o CMT se comprova como uma ótima ferramenta para detecção de mastites subclínicas nos rebanhos.

A utilização do CMT tem como vantagem ser empregado no início da ordenha dos quais os primeiros jatos de leite podem ser considerados com alta concentração de micro-organismos patogênicos relacionados com a mastite, o que pode ser fonte de contaminação para os animais e o ambiente (Zafalon et al. 2007).

Observou-se com esse estudo que poucos produtores examinam os três primeiros jatos de leite, apesar da recomendação de iniciar-se a ordenha com o exame dos primeiros jatos e posteriormente higienizar os tetos e seca-los com papel toalha individual assegurando assim que somente tetos limpos e secos são ordenhados (Zafalon et al. 2007).

Pode-se observar que as variáveis estudadas apresentam um fator em comum que é a forma como os animais são manejados durante a ordenha. 0 manejo durante a ordenha sofre uma grande influência da mão de obra utilizada, assim se vê a importância de treinamento para a mesma.

Pode-se observar com os dados analisados no presente trabalho, que os cuidados do ordenhador, no momento da ordenha, são um dos pontos de maior importância em todo o processo, pois, da qualificação e do envolvimento desse elemento, dependerá a efetiva execução de todas as recomendações oriundas de inúmeras reuniões técnicas e dispendiosas pesquisas realizadas em todo mundo (Souza 2005).

Quanto as análises microbiológicas realizadas durante o estudo verificou-se resultados semelhante ao de Freitas et al. (2005), em estudo de mastite subclínica bovina do Agreste do Estado de Pernambuco, onde os agentes mais prevalentes encontrados foram os SCN totalizando 36\%.

Alta incidência de isolamento do grupo de bactérias SCN nas amostras deste trabalho pode estar relacionada à resistência a diversos antibióticos utilizados rotineiramente no tratamento da mastite (Freitas et al. 2005). Também pode estar ligada a baixa eficiência de desinfetantes comerciais utilizados no pré e pós-dipping, frisando a importância de se monitorar a eficiência dos mesmos para a prevenção das mastites (Ramalho et al. 2012).

Ocorre uma grande amplitude de percentual de agentes isolados como no trabalho de Souza (2005), onde a ampli- tude dos grupos encontrados em mastites subclínicas varia de 2,4 a $53 \%$ para SCP, de 2,9 a $39,3 \%$ para SCN e 0,3 a 49,6 para Streptococcus spp. e outros.

0 tipo de ordenha e as características das ordenhadeiras são parâmetros importantes a se considerar, pois é comprovada a associação desses com a ocorrência de mastites subclínicas ocasionadas por Staphylococcus coagulase negativo. Algumas características devem ser levadas em consideração, pois podem contribuir para o deslizamento do conjunto de teteiras e possível contaminação dos insufladores com bactérias do ambiente, como peso do conjunto de teteiras, carência de manutenção do equipamento de ordenha e ordenha de tetos molhados.

A falta de manutenção dos equipamentos de ordenha, pode acarretar no excesso ou deficiência na quantidade de vácuo na ponta do conjunto de teteiras e funcionamento inadequado dos pulsadores os quais são uns dos principais fatores ligados ao equipamento que levam ao aparecimento de mastites subclínicas causadas por SCN (Reis et al. 2007). Isso se explica devido ao dano que essas imperfeições causam na ponta do teto (prolapso de esfíncter), aumentando a chance dos patógenos causadores das mastites invadirem o sistema mamário, pois o esfíncter serve como uma barreira natural contra os mesmos.

Segundo Bradley (2002) a redução da duração e a eliminação das infecções já estabelecidas podem ser alcançadas por meio da terapia da vaca seca em todos os animais.

A não secagem dos tetos antes da ordenha e a utilização de panos comuns para secagem de um grande número de tetos assim com a não higienização da mão do ordenhador poderiam estar funcionando como "ponte" ou fonte ambiental para disseminar agentes da mastite subclínica como SCN entre animais do rebanho.

Souza (2005) também identificou fatores de risco ligados ao isolamento de SCN para mastite subclínica, dos quais são destaque "Não lavar os tetos", "Realizar o exame dos três primeiros jatos", "Forma de aplicação do tratamento para mastite", "Níveis inadequados de vácuo na ponta da teteira" e as chances de isolamento de SCN ocorrer são 2.44, 2.58, 5.99, 1.50 respectivamente.

Em função da atual situação encontrada no presente trabalho, é importante avaliar o nível de conhecimento técnico dos produtores sobre as boas práticas de manejo relacionadas à produção de leite de alta qualidade, minimizando os prejuízos com as mastites subclínicas. Com esse intuito, Olival et al. (2004) analisaram a situação dos produtores de leite da região de Pirassununga-SP e avaliaram a percepção destes com relação à qualidade do leite, ou seja, como esse tema era entendido pelos produtores e o que eles sabiam a respeito desse assunto. Embora muito deles demonstrassem ter conhecimento sobre a existência da mastite, a maioria não sabiam listar os principais prejuízos causados por essa doença e suas medidas de prevenção.

Além do conhecimento adquirido por parte dos produtores em palestras e cursos sobre os problemas que a mastite causa, há a necessidade da mudança de hábitos destes através do comprometimento no controle de novos casos de mastites como, por exemplo, a utilização periódica do teste de CMT (Tavolaro et al. 2006). 
Com exceção das salas com ordenha canalizada, um fator observado durante as coletas era a falta de higienização das salas de ordenha, que eram realizadas com baixa frequência. Porém, não menos importante que a limpeza do equipamento de ordenha, é a limpeza do ambiente, como sala de leite e sala de ordenha, os quais devem ser limpos diariamente e com produtos adequados (Oliveira et al. 2009).

\section{CONCLUSÕES}

Verificou-se no presente trabalho que os fatores de risco ligados ao momento da ordenha que mais contribuem para casos de mastite subclínica em propriedades leiteiras são: tipo de ordenha, secagem dos tetos antes da ordenha, tratamento para casos de mastite clínica, higiene das mãos do ordenhador e treinamento dos ordenadores. Staphylococcus coagulase negativo, foi o agente mais prevalente nos isolamentos microbiológicos das amostras de leite com mastite subclínica.

Com isso, ressalta-se a importância do bom manejo de ordenha para prevenção da mastite subclínica nos rebanhos leiteiros.

\section{REFERÊNCIAS}

Barkema H.W., Schukken Y.H., Lam T.J., Beiboer M.L., Benedictus G. \& Brand A. 1998. Management practices associated with low, medium, and high somatic cell counts in bulk milk. J. Dairy Sci. 81(7):1917-1927.

Bradley J.D. 2002. Bovine mastitis: an evolving disease. Vet. J. 164(2):116128.

Brasil 2011. Estabelece o regulamento fixar os requisitos mínimos que devem ser observados para a produção, a identidade e a qualidade do leite. Instrução Normativa $n^{\circ}$ 62, de 29 de dezembro de 2011. Diário Oficial da República Federativa do Brasil, Poder Executivo, Brasília, DF, 1:6.

Brito J.R.F., Caldeira G.A.V., Verneque R.S. \& Brito M.A.V.P. 1997. Sensibilidade e especificidade do "Califórnia Mastite Test" como recurso diagnóstico da mastite subclínica em relação a contagem de células somáticas. Pesq. Vet. Bras. 17(2):49-53.

Coentrão C.M., Souza G.N., Brito J.R.F., Paiva e Brito M.A.V. \& Lilenbaum W. 2008. Fatores de risco para mastite subclínica em vacas leiteiras, Arq. Bras. Med. Vet. Zootec. 60(2):283-288.

Crivisqui E. 1995. Présentation de l'analyse factorielle des correspondances simples et multiples: Programe de Recherche et D'Enseignement em Statistique Appliquée (PRESTA), p.162. Université Libre de Bruxelles, Belgique.

Dumalisile P., Witthuhn R.C. \& Britz T.J. 2005. Impact of different pasteurization temperatures on the survival of microbial contaminants isolated from pasteurized milk. Int. J. Dairy Technol. 58(2):74-82.

Frankena K. \& Graat E.A.M. 1997. Multivariate analysis: logistic regression, p.135-178. In: Noordhuizen J.P.T.M., Frankena K. \& Van der Hoofd C.M. (Eds), Application of Quantitative Methods in Veterinary Epidemiology. Wageningen Press, Wageningen.

Fonseca L.F.L. \& Santos M.V. 2000. Qualidade do Leite e Controle da Mastite. Lemos, São Paulo, p.175.

Freitas M.F.L., Pinheiro Júnior J.W., Stamford T.L.M., Rabelo S.S.A., Silva D.R., Silveira Filho V.M., Santos F.G.B., Sena M.J. \& Mota R.A. 2005. Perfil de sensibilidade antimicrobiana in vitro de Staphylococcus coagulase positivos isolados de leite de vaca com mamite no Agreste do Estado de Pernambuco. Arqs Inst. Biológico, São Paulo, 72(2):171-177.

Hosmer D.W. \& Lemeshow S. 2000. Applied Logistic Regression. John Wiley and Sons, New York. 375p.

IBGE 2016. Estatística da Produção Pecuária, Março de 2016. Instituto Brasileiro de Geografia e Estatística. Disponível em: <http://www.ibge. gov.br/home/estatistica/indicadores/agropecuaria/producaoagropecuaria/abate-leite-couro-ovos_201504_publ_completa.pdf> Acesso em 1 jun. 2016.

Jorge A.M., Andrighetto C., Strazza M.R.B., Correa R.C., Kasburgo D.G., Piccinin A., Victória C. \& Domingues P.F. 2005. Correlação entre o California Mastitis Test (CMT) e a contagem de células somáticas (CCS) do leite de búfalas Murrah. Revta Bras. Zootec. 34(6):2039-2045.

Kubrusly L.S. 2001. Um procedimento para calcular índices a partir de uma base de dados multivariados. Pesq. Operacion. 21(1):107-117.

Lange M.J., Zambom M.A., Ramos C.E.C.O., Castagnara D.D., Bánkuti F.I., Neumann M.E., Brito M.M. \& Tinini R.C.R. 2016. Typology of dairy production systems based on the characteristics of management in the Region of West Paraná. Semina, Ciênc. Agrárias 37(1):473-482.

Lancette G.A., Tatini S.R., Vanderzant C. \& Splittstoesser D.F. 1992. Compendium of Methods for the Microbiological Examination of Foods. APHA, Washington, p.533-547.

Le Roux B. \& Rouanet H. 2010. Multiple Correspondence Analysis. SAGE, London.

Lebart L., Morineau A. \& Piron M. 2004. Statistique Exploratoire Multidimensidnnelle. Dunod, Paris. 439p.

Mattos M.R., Beloti V., Tamanini R., Magnani D.F., Nero L.A., Barros M.A.F., Pires E.M.F. \& Paquereau B.P.D. 2010. Qualidade do leite cru produzido na região do agreste de Pernambuco, Brasil. Semina, Ciênc. Agrárias 31(1):173-182.

MacFaddin J.F. 1980. Pruebas Bioquímicas para la Identificación de Bacterias de Importancia Clinica. Panamericana, Buenos Aires. 301p.

Mingoti S.A. 2005. Análise de Dados através de Métodos de Estatística Multivariada: uma abordagem aplicada, UFMG, Belo Horizonte. 297p.

Mota R.A., Medeiros E.S., Santos M.V., Pinheiro Júnior J.W., Moura A.P.B.L. \& Coutinho L.C.A. 2012. Participação dos Staphylococcus spp. na etiologia das mastites em bovinos leiteiros no estado de Pernambuco, Brasil. Ciênc. Anim. Bras. 13:124-130.

Nero L.A., Mattos M.R., Beloti V., Barros M.A., Pinto P.A.N., Andrade N.J., Silva N.J. \& Franco D.G.M. 2005. Leite cru de quatro regiões leiteiras brasileiras: perspectivas de atendimento dos requisitos microbiológicos estabelecidos pela Instrução Normativa 51. Ciênc. Tecnol. Alim. 25:191195.

Olival A.A., Spexoto A.A., Mano G.B. \& Santos M.V. 2004. Avaliação das limitações para melhoria da qualidade do leite na região de Pirassununga/ SP. Revta Ciênc. Extens., Botucatu, 1:171-183.

Oliveira A.A., Melo C.B. \& Azevedo H.C. 2009. Diagnóstico e determinação microbiológica da mastite em rebanhos bovinos leiteiros nos tabuleiros costeiros de Sergipe. Ciênc. Anim. Bras. 10(1):226-230.

Philpot N.W. \& Nickerson S.C. 2002. Vencendo a Luta contra a Mastite. Milk Bizz, Piracicaba, p.54-89.

Ramalho A.C., Soares K.D.A., Silva D.F., Barros M.R.C., Pinheiro Júnior J.W., Oliveira J.M.B., Mota R.A. \& Medeiros E.S. 2012. Eficácia in vitro de desinfetantes comerciais utilizados no pré e pós-dipping frente a Staphylococcus spp. isolados em rebanhos leiteiros. Pesq. Vet. Bras. 32(12):12851288.

Reis G.L., Alves A.A., Lana A.M.Q., Coelho S.G., Souza M.R., Cerqueira M.M.O.P., Penna C.F.A.M. \& Mendes E.D.M. 2007. Procedimento de coleta de leite cru individual e sua relação com a composição fisioquímica e a contagem de células somáticas. Ciência Rural 37(4):1134-1138.

Santana E.H.W., Beloti V., Barros M.A.F., Moraes L.B., Gusmão V.V. \& Pereira M.S. 2001. Contaminação do leite em diferentes pontos do processo de produção: microrganismos aeróbios mesófilos e psicotróficos. Semina, Ciênc. Agrárias 22:145-154.

Silva E.R., Araujo A.M., Alves F.S.F., Pinheiro R.R. \& Saukas T.N. 2001.Associação entre o Califórnia Mastitis Test e a Contagem de Células Somáticas na avaliação da saúde da glândula mamária caprina. Revta Bras. Vet. Ciênc. Anim. 38(1):46-48.

Smith R.R., Moreira V.M. \& Latrille L.L. 2002. Caracterización de sistemas productivos lecheros en la X región de Chile mediante análisis multivariable. Agric. Téc. 62(3):375-395. 
Souza G.N. 2005. Fatores de risco para mastite bovina. Tese de Doutorado em Medicina Veterinária, Escola de Veterinária, Universidade Federal de Minas Gerais, Belo Horizonte.

Taponen S. \& Pyörälä S. 2009. Coagulase-negative staphylococci as cause of bovine mastitis: not so different from Staphylococcus aureus? Vet. Microbiol. 134:29-36.
Tavolaro P., Oliveira C.A.F. \& Lefèvre F. 2006. Avaliação do conhecimento em práticas de higiene: uma abordagem qualitativa. Interface-Comunic., Saúde, Educ., Botucatu, 10(19):243-254.

Zafalon L.F., Nader Filho A., Oliveira J.V. \& Resende F.D. 2007. Mastite subclínica causada por Staphyloococcus aureus: custo benefício da antibioticoterapia de vacas em lactação. Arq. Bras. Med. Vet. Zootec. 59:577-585. 